\title{
Análise da cobrança pelo uso de recursos hídricos em águas de domínio da União: Estudo de caso da bacia hidrográfica do rio Doce (MG)
}

\author{
Analysis of the collection for the use of water resources in Union-dominated waters: Case study of \\ the Doce river watershed (MG) \\ Análisis de la tarificación por el uso de los recursos hídricos em aguas de poder de la Unión: \\ Estudio de caso de la cuenca hidrográfica del río Doce (MG)
}

\begin{abstract}
Resumo
O uso intensivo dos recursos naturais provoca impactos cada vez maiores ao meio ambiente. A água é um dos recursos mais afetados, pois dela dependem as diversas atividades humanas, o que tem colocado em risco sua disponibilidade em quantidade e qualidade. A partir da constatação da possibilidade de escassez, houve a necessidade de reconhecer a água como um recurso natural limitado e, portanto, dotado de valor econômico. Esse princípio é o que baseia o instrumento da cobrança pelo uso dos recursos hídricos, regulamentado pela Lei Federal n 9.433/1997, que instituiu a Política Nacional de Recursos Hídricos. O presente trabalho teve como escopo o estudo desse instrumento, particularmente em águas de domínio da União na bacia hidrográfica do Rio Doce. O trabalho pautou-se na coleta, sistematização e interpretação de informações por meio de pesquisa documental e bibliográfica. Os resultados apresentaram que apesar dos avanços obtidos com a cobrança, ainda existem limitações a serem sanadas, como a inadimplência na bacia em estudo, insuficiência dos valores arrecadados para realização de ações na bacia hidrográfica e baixa eficiência dos recursos desembolsados. Assim, deve-se criar um ambiente de constante consolidação e melhoria do instrumento, para de fato induzir e estimular a conservação, o manejo integrado e a recuperação dos recursos hídricos.
\end{abstract}

Palavras-chave: Cobrança de recursos hídricos; Instrumento de gestão; Bacia hidrográfica do rio doce.

\begin{abstract}
The intensive use of natural resources has caused increasing impacts on the environment. Water is one of the most affected resources, because the various human activities depend on it for its operation, and this endangers its availability in quantity and quality. On the possibility of scarcity, it was necessary to recognize water as a limited natural resource and, therefore, endowed with economic value. The water use charge instrument is based on this principle, established by Law 9.433/1997, which established the National Water Resources Policy. The present work had as objective the study of this instrument, particularly in waters under the domain of the Doce River Basin Union. The research was based on the collection, systematization and interpretation of information through documentary and bibliographical research. The results showed that despite the advances made with the instrument, there are still limitations to be resolved, such as default in the basin under study, insufficient amounts collected to perform actions in the watershed and low efficiency of disbursed resources. Thus, an environment of constant consolidation and improvement of the instrument should be created, in fact to induce and stimulate conservation, integrated management and recovery of water resources.
\end{abstract}

Keywords: Collection of water resources; Doce river watershed; Management instrument. 


\begin{abstract}
Resumen
El uso intensivo de los recursos naturales tiene un impacto cada vez mayor en el medio ambiente. El agua es uno de los recursos más afectados, porque las diversas actividades humanas dependen de él, lo que ha puesto en riesgo su disponibilidad en cantidad y calidad. A partir de la toma de conciencia de la posibilidad de escasez, surgió la necesidad de reconocer el agua como un recurso natural limitado y, por tanto, dotado de valor económico. Este principio es la base del instrumento de tarificación por el uso de los recursos hídricos, regulado por la Ley Federal $n^{\circ}$. 9.433/1997, que instituyó la Política Nacional de Recursos Hídricos. El presente trabajo tuvo como alcance el estudio de este instrumento, particularmente en aguas de dominio de la Unión en la cuenca hidrográfica del Río Doce. El trabajo se basó en la recopilación, sistematización e interpretación de información a través de la investigación documental y bibliográfica. Los resultados mostraron que a pesar de los avances obtenidos con la recaudación, aún existen limitaciones por resolver, como la morosidad en la cuenca en estudio, la insuficiencia de los montos recaudados para realizar acciones en la cuenca hidrográfica y la baja eficiencia de los recursos desembolsados. Por tanto, se debe crear un entorno de constante consolidación y mejora del instrumento, para inducir y estimular realmente la conservación, la gestión integrada y la recuperación de los recursos hídricos.
\end{abstract}

Palabras clave: Cuenca hidrográfica del río doce; Instrumento de gestión; Tarificación de los recursos hídricos.

\title{
1. Introdução
}

A gestão dos recursos hídricos tem se tornado um desafio para os governos e os problemas relacionados à água doce no mundo têm sido objeto de discussões diversas. A crescente degradação da sua qualidade e quantidade têm ocasionado problemas reais de escassez, comprometimento de setores produtivos e até mesmo o abastecimento de cidades, elevando custos de tratamento e a necessidade do uso de sistemas de transporte de água a longas distâncias para abastecimento urbano.

Particularmente, tratando-se da realidade nacional, o Brasil é um país com vasta extensão territorial, e apesar da abundância de água, possui diferentes problemas, sendo eles principalmente relacionados a disponibilidade de água em função dos aspectos hidrogeográficos, aumento de demanda em regiões urbanizadas, precariedade ou inexistência de saneamento básico, poluição, carências no exercício da legislação, entre outros fatores que evidenciam a necessidade da gestão sustentável desse recurso (Vera, 2014).

O Brasil é um país com grande disponibilidade hídrica. No entanto, expõe também situações conflituosas de abundância e escassez de água, sendo necessário dos governos, dos usuários e da sociedade civil, um melhor planejamento na gestão de sua utilização e na solução para inúmeros conflitos que podem surgir (Fonseca et al., 2020).

Em termos legislativos, o Brasil possui a Política Nacional de Recursos Hídricos (PNRH), instituída pela Lei Federal n. 9.433/1997, que é um dos principais respaldos legislativos brasileiros que primam pelo uso sustentável da água, ou seja, pela garantia do seu uso, em quantidade e qualidade, para presentes e futuras gerações. A Lei em questão, mais conhecida como Lei das Águas, é considerada o diploma legal de recursos hídricos no Brasil e foi a partir dela que a gestão de recursos hídricos obteve avanços significativos, pois estruturou, orientou e modernizou a gestão das águas no país (ANA, 2017).

A PNRH tem quatro objetivos principais: I - assegurar à atual e às futuras gerações a necessária disponibilidade de água, em padrões de qualidade adequados aos respectivos usos; II - incentivar a utilização racional e integrada dos recursos hídricos com vistas ao desenvolvimento sustentável; III - a prevenção e a defesa contra eventos hidrológicos críticos de origem natural ou decorrentes do uso inadequado dos recursos naturais; e IV - a prevenção e a defesa contra eventos hidrológicos críticos de origem natural ou decorrentes do uso inadequado dos recursos naturais (Brasil, 1997).

Essa mesma lei criou o Sistema Nacional de Gerenciamento de Recursos Hídricos (SINGREH), foram estabelecidos instrumentos de gestão com vistas a alcançar os objetivos da PNRH. São eles: Planos de Recursos Hídricos; Enquadramento dos corpos de água em classes, segundo seus usos preponderantes; Outorga dos direitos de uso de recursos hídricos; Sistema de Informações sobre Recursos Hídricos (SNIRH); e Cobrança pelo uso de recursos hídricos.

A cobrança pelo uso de recursos hídricos, objeto deste estudo, é um instrumento econômico com vistas a alcançar o objetivo da gestão sustentável da água que permite a geração de receita para subsidiar intervenções nas bacias hidrográficas 
para a manutenção da qualidade e quantidade de água. Os mecanismos e valores a serem cobrados são definidos no âmbito dos Comitês de Bacia Hidrográfica (CBHs), com a participação de diversos setores.

A cobrança tem como finalidade criar o equilíbrio entre a oferta e a demanda do bem, harmonizando a competição entre os usuários da bacia (Munck, 2006; Pessoa, 2002). Yassuda (1993) aponta esse instrumento como um dos mais eficazes em regiões onde a escassez de recursos hídricos exige investimentos que venham a garantir o equilíbrio entre a oferta e a demanda, no interesse de todos.

De todos os instrumentos instituídos pela PNRH, o instrumento da cobrança pelo uso de recursos hídricos é considerado um dos mais polêmicos e complexos. Thomas (2002) cita alguns motivos em sua obra, como a pluralidade de atores envolvidos no processo, seus interesses e a diversidade de metodologias existentes.

Cabe ressaltar que antes da implementação da cobrança, são necessários estudos que avaliem os impactos desse instrumento sobre os setores usuários da bacia, uma vez que deve gerar receita e estimular a racionalização do uso da água, e não inviabilizá-lo, o que pode originar outros problemas de âmbito social ou econômico (Leal, 2010).

A Lei das Águas estabelece que a cobrança incida sobre os usos sujeitos a outorga de direito de uso dos recursos hídricos. Portanto, seu cálculo é determinado em função da vazão autorizada para uso, ou seja, vazão de captação, lançamento e/ou consumo. A captação consiste na parcela de água retirada para determinado uso; o lançamento ou diluição é a parcela de água necessária para diluir efluentes; e o consumo se refere à água que não retorna diretamente ao corpo hídrico, ou seja, a diferença entre a vazão de água outorgada para a captação e a vazão do efluente lançada no corpo hídrico.

No que diz respeito à operacionalização da cobrança, diferentes entidades e órgãos participam desse processo com diferentes funções. Quanto aos corpos d'água de domínio da União, ou seja, aqueles que atravessam mais de um estado, a Agência Nacional de Águas e Saneamento Básico (ANA) é a responsável pela regulação do uso da água e pela implementação dos instrumentos de gestão definidos pela PNRH. A ANA também fica encarregada de arrecadar e distribuir os recursos advindos da cobrança às respectivas Agências de Água das bacias em questão (Brasil, 1997).

Em âmbito estadual, os órgãos gestores são encarregados de arrecadar as receitas da cobrança, por exemplo: o Instituto Mineiro de Gestão das Águas - Igam (Minas Gerais); Companhia de Gestão de Recursos Hídricos (Ceará); Instituto Estadual do Ambiente (Rio de Janeiro); e o Departamento de Águas e Energia Elétrica (São Paulo) (OCDE, 2017).

No que tange a aplicação dos recursos arrecadados, o art. 22 da Lei n. 9.433/1997 dispõe que os valores da cobrança serão aplicados prioritariamente na bacia hidrográfica em que foram gerados. Esses recursos devem ser aplicados em financiamento de estudos, programas, projetos e obras incluídos nos Planos de Recursos Hídricos, bem como para o pagamento de despesas de implantação e custeio administrativo dos órgãos e entidades integrantes do SINGERH, limitado a 7,5\% do total arrecadado. Os valores arrecadados poderão ainda ser aplicados a fundo não reembolsáveis, em projetos e obras que alterem de modo considerado benéfico à coletividade, a qualidade, a quantidade e o regime de vazão de um corpo de água (Brasil, 1997).

Silva (2020) analisou a efetividade da cobrança pelo uso de recursos hídricos no Comitê da Bacia Hidrográfica do Rio Araguari (MG) - CBH Araguari. Os resultados demonstraram que os recursos oriundos da cobrança pelo uso de recursos hídricos são aplicados conforme os programas definidos nos Planos Plurianuais de Aplicação (PPA), mantendo-se a correlação com as componentes instituídas no Plano Diretor de Recursos Hídricos (PDRH) da bacia.

Fica evidente que a cobrança pelo uso dos recursos hídricos é um meio de alcançar objetivos importantes para solucionar problemas vinculados à progressiva degradação da qualidade das águas e redução da sua disponibilidade.

A primeira bacia de domínio da União a dar início ao processo da cobrança foi a Bacia Hidrográfica do Rio Paraíba do Sul, cujo pioneirismo representou uma referência para outras bacias interestaduais e estaduais. A aprovação pelo Conselho 
Nacional de Recursos Hídricos (CNRH) dos mecanismos e valores definidos pelo Comitê de Integração da Bacia Hidrográfica do Rio Paraíba do Sul ocorreu em 2002 e a cobrança foi efetivamente iniciada em 2003.

A Bacia Hidrográfica do Rio Doce foi a quarta experiência que teve a cobrança em rios federais, iniciada no ano de 2011. A implantação da cobrança na bacia do Rio Doce foi motivada pelo aumento dos usos da água na bacia atrelados ao aumento da urbanização e do desenvolvimento econômico da região.

O Comitê de Bacia Hidrográfica do Rio Doce (CBH-Doce) optou por não considerar em seus mecanismos a parcela "consumo". Este detalhe facilita o entendimento do usuário e simplifica os procedimentos operacionais (Leal, 2010).

A cobrança pelo uso de recursos hídricos está em operação no estado de Minas Gerais desde 2010, quando foi implantada em três bacias. Observa-se que poucas foram as mudanças em prol de seu aprimoramento, ainda que a necessidade de avanços e melhorias tenha sido debatida e recomendada em várias instâncias de participação (Rosa, 2019).

Para a implementação da cobrança, a discussão ocorreu de forma simultânea em todos os cômites da bacia e com atuação dos órgãos outorgantes, evidenciando o processo de gestão integrada de recursos hídricos. Desta forma, a cobrança também se encontra implementada nas bacias mineiras afluentes do Rio Doce, ou seja, Rio Piracicaba, Rio Santo Antônio, Rio Piranga, Rio Manhuaçu, Rio Caratinga e Rio Suaçuí.

Quanto às bacias do Espírito Santo afluentes ao Rio Doce, a cobrança ainda não foi implementada (Rio Santa Joana, Rio Santa Maria do Rio Doce, Rio Guandu, Barra Seca e Foz do Rio Doce, Pontões, São José e Lagos do Rio Doce). Em abril de 2011, os CBH's do Rio Guandu e do Rio São José deliberaram sobre a cobrança, mas seu início efetivo depende de regulamentação do instrumento pela Assembleia Legislativa, conforme prevê a política de recursos hídricos do Estado do Espírito Santo (Brasil, 2018a).

Diante da representatividade da Bacia do Rio Doce para a região onde está inserida, tanto em termos sociais, econômicos e ambientais, a aplicação e o aprimoramento de instrumentos de gestão ambiental são indispensáveis para a manutenção dos recursos hídricos e a mitigação dos problemas de degradação cada vez mais recorrentes.

Nesse sentido, este trabalho teve como objetivo principal avaliar a cobrança pelo uso de recursos hídricos como instrumento de gestão na Bacia Hidrográfica do Rio Doce, no que concerne a obtenção e aplicação de recursos financeiros para o financiamento de intervenções na bacia hidrográfica em questão. Como a adoção da cobrança ainda é considerada relativamente recente no Brasil, espera-se que este trabalho contribua para discussões sobre esse tema.

\section{Metodologia}

A investigação científica depende de um conjunto de procedimentos intelectuais e técnicos adotados para que seus objetivos sejam atingidos (Prodanov \& Freitas, 2013). A presente pesquisa prima por analisar a cobrança pelo uso de recursos hídricos no que concerne aos recursos arrecadados na Bacia do Rio Doce, em rios de domínio da União. Para atender ao objetivo principal, faz-se necessário inicialmente a delimitação das principais características da pesquisa no campo da metodologia científica, bem como realizar uma caracterização geral do universo da pesquisa, isso é, a Bacia Hidrográfica do Rio Doce.

\subsection{Caracterização do estudo quanto aos procedimentos}

De acordo com a classificação de Turrioni e Mello (2012) as pesquisas podem ser classificadas em qualitativas e quantitativas, segundo a abordagem do problema. A presente pesquisa voltou-se principalmente a abordagem qualitativa. Apesar de haver a comparação de dados numéricos, proposta nos objetivos específicos, a interpretação dos mesmos é de caráter qualitativo. Ademais, não menos importante, foi necessária a pesquisa explicativa para identificar os fatores que determinam ou contribuem para a ocorrência dos fenômenos. 
Quanto ao atendimento dos objetivos propostos, o trabalho tem característica de pesquisa descritiva, o que significa identificar e comparar, para descrever os fatos e fenômenos de determinada realidade, segundo a concepção de Silva (2003). A pesquisa descritiva foi determinada pelo estabelecimento de relação entre variáveis, como a comparação entre valores cobrados e arrecadados. Assim mostrará a adimplência dos usuários na bacia em questão e consequentemente procurará estabelecer uma relação com o atendimento do terceiro objetivo da cobrança trazido pela PNRH, isto é, o de obter recursos para o financiamento das intervenções contempladas no Plano Integrado de Recursos Hídricos da Bacia do Rio Doce - PIRH Doce.

Este estudo foi embasado principalmente na coleta, sistematização e interpretação de informações, originárias de documentos, que constituíram as fontes primárias, como também informações secundárias, como relatórios técnicos e tabelas. Para a coleta e análise de dados, lançou-se mão da pesquisa documental, bibliográfica e estudo de caso.

Foram consultados tabelas e gráficos da ANA sobre os valores da cobrança da Bacia do Rio Doce em rios da União, além do SNIRH e dados do Cadastro Nacional de Usuários de Recursos Hídricos (CNARH). Ademais, foram consultados o Plano de Gerenciamento Integrado de Recursos Hídricos do Rio Doce (PIRH- Doce) e seus respectivos Planos de Ações para as Unidades de Planejamento e Gestão de Recursos Hídricos (PARH's), como também dados do Instituto BioAtlântica - IBioAGB Doce.

\subsection{Caracterização da área de estudo}

A pesquisa teve como área de estudo a Bacia Hidrográfica do Rio Doce, especificamente águas de domínio da União, para avaliar os valores da cobrança arrecadados e aplicados na bacia até o exercício de 2018.

O rio Doce é formado a partir do encontro do rio do Carmo e rio Piranga, cuja nascente localiza-se na Serra da Mantiqueira. Suas águas percorrem aproximadamente $853 \mathrm{~km}$ desde a nascente até sua foz que está localizada próxima ao povoado de Regência, município capixaba de Linhares (Igam, 2010). Por englobar dois estados, é considerado um rio de domínio federal, conforme o que dispõe o art. 20, inciso III da Constituição Federal (Brasil, 1988).

Localizada na Região Hidrográfica do Attântico Sudeste, no Sudeste do Brasil, a bacia do Rio Doce abrange um total de 228 municípios (202 mineiros e 26 capixabas). Compreende uma população de aproximadamente 3,5 milhões de habitantes, que em sua maioria reside em centros urbanos - 73\% (ANA, 2013). A bacia possui uma significativa extensão territorial, com uma área de drenagem de aproximadamente $86 \mathrm{mil} \mathrm{km}^{2}$, dos quais $86 \%$ situam-se em Minas Gerais e o restante no estado do Espírito Santo (Igam, 2010).

Por se tratar de uma bacia de domínio da União e ainda abranger cursos d'água de domínio dos estados, a gestão da Bacia Hidrográfica do Rio Doce é realizada pela ANA, Instituto de Meio Ambiente e Recursos Hídricos (IEMA) e IGAM, que atuam de maneira conjunta para garantir a implementação da PNRH.

Para facilitar o planejamento e execução das diretrizes traçadas pelo PIRH Doce, a Bacia foi subdividida em nove unidades de gestão, de acordo com seus principais afluentes, com base nas curvas de nível digitalizadas das cartas do Instituto Brasileiro de Geografia e Estatística - IBGE (Igam, 2010). Em Minas Gerais existem seis Unidades de Planejamento e Gestão dos Recursos Hídricos, a saber: DO1 - CBH do rio Piranga; DO2 - CBH do rio Piracicaba; DO3 - CBH do rio Santo Antônio; DO4 - CBH do rio Suaçuí; DO5 - CBH do rio Caratinga; e DO6 - CBH do rio Manhuaçu. Já o Estado do Espírito Santo é formado por três Unidades de Análise formadas pelo: CBH do rio Guandu; CBH do rio São José; e CBH do rio Santa Maria do Doce.

Em âmbito federal, tem-se ainda o CBH-Doce que é responsável pelas águas de domínio da União que conta com o apoio da ANA para seu funcionamento. Quanto aos estados, as subdivisões estão representadas na Figura 1. 
Figura 1 - Subdivisões da Bacia Hidrográfica do Rio Doce.

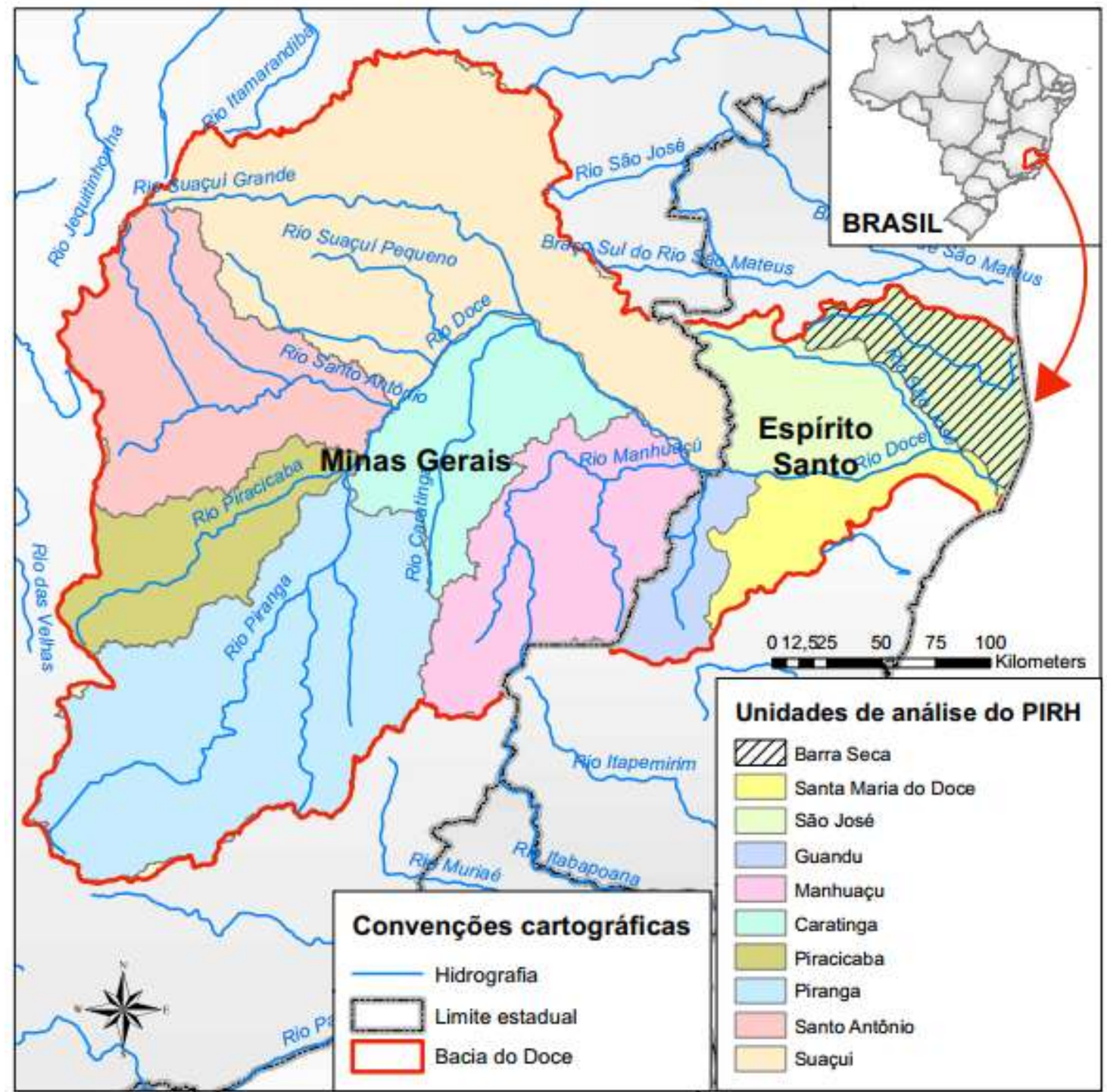

Fonte: ANA (2014).

A bacia sofreu intenso processo de supressão da vegetação original, sobretudo no século XX, devido ao aumento das pressões antrópicas e aumento das atividades econômicas. A estrada de ferro Vitória-Minas foi relevante nesse processo, uma vez que possibilitou a efetiva ocupação do território da bacia e aumentou a dinamização da economia, o que consequentemente acarretou pressões sobre os recursos hídricos (Igam, 2010).

Atualmente, a bacia do Rio Doce apresenta grande diversidade de atividades econômicas. Segundo o Igam (2010), as principais atividades são: a indústria (celulose, siderurgia e laticínios); a agropecuária (reflorestamento, lavouras tradicionais, cultura de café, cana-de-açúcar, criação de gado leiteiro e de corte e suinocultura); a agroindústria (sucroalcooleira); o comércio e serviços de apoio aos complexos industriais; geração de energia elétrica; e a mineração (ferro, ouro, bauxita, manganês, pedras preciosas e outros).

A maior concentração industrial está localizada na região do rio Piracicaba, onde o Produto Interno Bruto (PIB) do setor industrial supera 50\% do PIB total da bacia. Vale também citar que nessa bacia encontra-se instalado o maior complexo siderúrgico da América Latina. Apesar da intensa atividade das empresas desse complexo e consequente geração de capital, o PIRH Doce aponta para a presença de desigualdades sociais significativas no interior da bacia, sendo que quase uma centena dos municípios é considerada pobre (Igam, 2010). 
A Bacia Hidrográfica do Rio Doce também possui um importante potencial hidrelétrico, com capacidade de geração de aproximadamente 1.230 MW (Igam, 2010). A região abriga 10 usinas hidrelétricas, sendo 4 delas localizadas no Rio Doce e 6 em seus afluentes, além de 29 pequenas centrais hidrelétricas (ANA, 2016).

Segundo dados de mapeamento e cobertura do solo do IBio (2016), o uso predominante corresponde a pastagem (60\%). A vegetação nativa ainda ocupa $27 \%$ do território, representando uma área aproximada de 2,4 milhões de hectares distribuídos em pequenos e médios fragmentos vegetativos, sobretudo nas regiões de cabeceira. As áreas agrícolas não possuem grande representatividade (5\%) sendo mais expressiva em regiões onde se predominam a cafeicultura. Importa acrescentar que a bacia do Rio Doce tem a maioria da sua extensão territorial inserida no bioma de Mata Atlântica, $5^{a}$ colocada na lista de hotspots, isto é, as regiões biologicamente mais ricas e ameaçadas do planeta (Mittermeier et al., 2005)

Uma característica da área de estudo, apontada pelo PIRH Doce, é a alta suscetibilidade a processos erosivos e vulnerabilidade ambiental. Os processos são causados pelas características de ordem natural, aliadas ao manejo inadequado do solo, o que resulta em solos com 58\% de susceptibilidade forte a erosão e 30\% de susceptibilidade média (Igam, 2010).

Os principais problemas ambientais destacados pelo PIRH Doce são: turbidez das águas, ocupação desordenada de margens fluviais, assoreamento de cursos d'água e poluição hídrica (Igam, 2010). O lançamento irregular de esgotos domésticos ainda é um problema significativo, em que dos 209 municípios que fazem parte da bacia, apenas 41 possuem serviços de coleta e tratamento de esgotos e destes 28 tratam mais da metade do esgoto gerado (ANA, 2016).

Por fim, importante destacar que o rio Doce foi alvo de um desastre ambiental de grande magnitude em novembro de 2015 causado pelo rompimento de uma barragem de rejeitos de minério, no distrito de Bento Rodrigues, município de Mariana. Os rejeitos percorreram mais de $650 \mathrm{~km}$ até atingir a foz do rio Doce causando impactos de grandes proporções.

\subsection{Metodologia de cobrança adotada na Bacia Hidrográfica do Rio Doce}

A cobrança pela água bruta adotada para corpos hídricos de domínio da União na Bacia do Rio Doce, estabelecida pela Deliberação CBH-Doce no 26/2011, atualizada recentemente pela Deliberação CBH-Doce $n^{\circ}$ 69/2018, considera vazões de captação de água bruta, sua transposição e o lançamento de efluentes (Brasil, 2011a, 2018a).

Os preços unitários propostos para o alcance de metas de desembolso dos recursos financeiros aprovadas no contrato de gestão celebrado entre a ANA e o IBio e aprovado pelo CBH-Doce estão apresentados na Tabela 1. 
Tabela 1 - Preços Públicos Unitários praticados na Bacia do Rio Doce.

\begin{tabular}{c|c|c|c|c|c|c|c|c|c}
\hline Tipo de uso & PPU* & Unidade & \multicolumn{7}{c}{ Preço unitário } \\
\hline \multicolumn{3}{c|}{ Ano } & $\begin{array}{c}\mathbf{2 0 1 1 /} \\
\mathbf{2 0 1 2}\end{array}$ & $\mathbf{2 0 1 3}$ & $\mathbf{2 0 1 4}$ & $\begin{array}{c}\mathbf{2 0 1 5} \\
\mathbf{2 0 1 7}\end{array}$ & $\mathbf{2 0 1 8}$ & $\mathbf{2 0 1 9}$ \\
\hline $\begin{array}{c}\text { Captação de } \\
\text { água bruta }\end{array}$ & PPUcap & $\mathrm{R} \$ / \mathrm{m}^{3}$ & 0,018 & 0,021 & 0,024 & 0,03 & 0,0308 & 0,0336 \\
\hline Transposição & PPUtrans & $\mathrm{R} \$ / \mathrm{m}^{3}$ & 0,022 & 0,027 & 0,031 & 0,04 & 0,0411 & 0,0448 \\
\hline $\begin{array}{c}\text { Lançamento } \\
\text { de efluentes }\end{array}$ & PPUlanç & $\begin{array}{c}\mathrm{R} \$ / \mathrm{kg} \text { de } \\
\mathrm{DBO}\end{array}$ & 0,1 & 0,12 & 0,15 & 0,16 & 0,0164 & 0,179 \\
\hline
\end{tabular}

*PPU: preço público unitário. Fonte: Adaptado de ANA (2018a).

A proposta do $\mathrm{CBH}-$ Doce optou por não considerar o consumo no cálculo da cobrança. A Fundação Arthur Bernardes, instituição de apoio a Universidade Federal de Viçosa, apontou em seus estudos de aprimoramento da cobrança na bacia do Rio Doce vários fatores que dificultam a operacionalização da cobrança, e que foram determinantes da retirada da parcela "consumo". Tais fatores são: complexidade operacional para calcular o volume de consumo quando há captações e lançamentos em rios de diferentes dominialidades; maior facilidade para os usuários no preenchimento do CNARH; pequeno incentivo ao uso racional da água, pois o usuário tem pouca sensibilidade quanto à diferença das parcelas captação e consumo (Funarbe, 2013).

De acordo com Almeida (2018, p. 68) “os organismos da bacia do Rio Doce acreditam que cobrar a parcela de consumo pode criar mais dificuldade do que servir como ferramenta de gestão efetiva para as águas, com a devida compreensão pelo usuário".

\section{Resultados e Discussão}

3.1 Valores cobrados e arrecadados na Bacia Hidrográfica do Rio Doce, em rios de domínio federal

A bacia hidrográfica do Rio Doce, quarta experiência brasileira com a cobrança pelo uso de recursos hídricos em rios de domínio federal, obteve a regulamentação necessária para iniciar a cobrança em novembro de 2011 (Brasil, 2011 b). Entretanto, somente no início de 2012 o instrumento foi efetivamente implementado, razão que determinou o período inicial para análise dos valores de cobrança na bacia.

A Tabela 2 apresenta os dados disponibilizados pela ANA que mostram um resumo dos valores anuais de cobrança, do período de 2012 a 2018, em águas de domínio da União na bacia do Rio Doce, sendo contabilizados os valores referentes captação de água bruta, transposição e lançamento de efluentes e seus respectivos preços unitários. 
Tabela 2 - Valor cobrado versus arrecadado pelo uso de recursos hídricos de domínio da União na bacia do Rio Doce - 2012 a 2018.

\begin{tabular}{c|c|c}
\hline Ano & Cobrado $(\mathbf{R} \$)$ & Arrecadado $(\mathbf{R} \$)$ \\
\hline 2012 & $10.342 .679,00$ & $3.438 .674,00$ \\
\hline 2013 & $8.404 .887,00$ & $6.505 .081,00$ \\
\hline 2014 & $9.817 .054,00$ & $9.729 .725,00$ \\
\hline 2015 & $12.577 .512,00$ & $10.699 .661,00$ \\
\hline 2016 & $11.041 .049,00$ & $9.188 .873,00$ \\
\hline 2017 & $11.966 .437,00$ & $11.263 .346,00$ \\
\hline 2018 & $10.076 .782,00$ & $12.304 .986,00$ \\
\hline Total & $\mathbf{7 4 . 2 2 6 . 4 0 0 , 0 0}$ & $\mathbf{6 3 . 1 3 0 . 3 4 6 , 0 0}$ \\
\hline
\end{tabular}

Fonte: ANA (2018a).

Destaca-se que primeiramente foram consultadas tabelas disponibilizadas pelo sítio do CBH-Doce. Entretanto foram encontradas divergências consideráveis, quando foram comparados os valores do CBH-Doce aos valores disponibilizados pela ANA.

Por exemplo, analisando-se os dados correspondentes a 2015 na Tabela 2, nota-se que a arrecadação efetiva representou um percentual de 85,07\%, valor que se assemelha ao percentual médio de arrecadação do período em análise $(85,05 \%)$. Já os dados referentes ao mesmo ano declarados pelo CBH-Doce (R $\$ 2.515 .162,17$ cobrados e R \$10.702.030,40 arrecadados) representam um percentual de arrecadação de 425,5\% (CBH-Doce, 2015), o que representa um valor destoante do percentual total de arrecadação identificado.

Ao notar discrepância considerável nos valores do CBH-Doce, deduziu-se que pode haver erro e por esse motivo, optou-se por adotar os dados disponibilizados pela ANA.

No período de 2012, a efetiva arrecadação representou apenas 33,25\% da cobrança prevista, que corresponde ao menor percentual de arrecadação entre os anos analisados, e, portanto, a maior inadimplência por parte dos usuários.

Desde o início da aplicação da cobrança até o ano de 2017 os montantes arrecadados eram sempre inferiores aos valores faturados. A inadimplência na arrecadação até o ano em questão representou R \$ 13.324.258,00, o que corresponde a aproximadamente $20 \%$ do valor total cobrado, valor considerado expressivo em relação à cobrança prevista. Entretanto, no ano de 2018 houve uma inversão dessa situação que correspondeu ao maior índice de recursos arrecadados, supostamente devido a juros e multas, casos de parcelamento da dívida e recebimento de anos anteriores. Esclarece-se que o usuário que não quita o valor devido até a data de vencimento fica sujeito às sanções da Lei Federal n 9 9.433/97 e normativos administrativos editados pela ANA (Brasil, 1997, 2013).

A diferença entre os montantes cobrados e arrecadados também pode ter relação com usuários que entraram com recurso de revisão de valores. Conforme o portal da ANA, caso o usuário considere o valor alto e o empreendimento não esteja utilizando toda a vazão outorgada, pode ser solicitada uma revisão da sua outorga. Ressalta-se que a revisão de valores estará regulamentada em uma resolução (atualmente em formato de minuta), válida a partir de $1^{\circ}$ de janeiro de 2020 . De acordo com esse documento, a cobrança poderá ser revista por solicitação do usuário de recursos hídricos mediante exposição fundamentada; ou ainda por meio de ofício, caso a ANA constate tal necessidade (ANA, 2019). 
De forma geral, desde o início da implantação da cobrança na bacia do Rio Doce, é possível notar um aumento gradativo nos valores arrecadados, o que mostra aceitação e aderência crescente por parte dos usuários, à medida que o hábito de pagar pelo uso da água se consolida. Analisando-se os montantes totais do período, a diferença entre o valor total faturado e os pagamentos realizados totalizam aproximadamente $\mathrm{R}$ \$11,1 milhões, o que equivale a $15 \%$ de inadimplência.

A arrecadação na bacia do Rio Doce a coloca em quarto lugar em relação às demais bacias de domínio da União, com participação de aproximadamente 11,1\% (ANA, 2018b). O valor pode ser atribuído ao fato da cobrança na bacia do Rio Doce ser relativamente recente em relação às bacias Paraíba do Sul, PCJ (Piracicaba, Capivari e Jundiaí) e São Francisco, que iniciaram a cobrança anteriormente (ANA, 2018c).

Contudo, os montantes arrecadados pela bacia do Rio Doce podem ser considerados importantes no cenário das bacias estratégicas brasileiras. Analisando-se sua arrecadação no período em estudo, os valores anuais perfazem uma média de aproximadamente de R\$ 9 milhões. Tal valor se aproxima da arrecadação média anual da bacia do Rio Paraíba do Sul, que iniciou a cobrança praticamente 9 anos antes, considerando que começou no início de 2003 (Bernardes \& Broch, 2015).

Tratando-se de valores, outro fato importante a ser ponderado é o balanço entre os montantes previstos e arrecadados na bacia do Rio Doce. Tendo em vista as demais bacias de domínio da União, a bacia do Rio Doce ocupa a segunda posição em inadimplência pelos valores totais não arrecadados (15\%), em que no primeiro lugar aparece a bacia do Verde Grande $(25,71 \%)$. Tendo em vista a média de inadimplências $(6 \%)$, nota-se que tal índice da bacia do Rio Doce é mais que o dobro da média nacional (ANA, 2018b).

Importante salientar que, de acordo com o PIRH Doce, com prognóstico para os anos de 2010 a 2020, o programa de investimentos é de cerca de R\$ 1,34 bilhão (ANA, 2013). Ao analisar a média anual de arrecadação, foi possível verificar que seriam necessários 137,5 anos para o alcance das metas de investimentos para a melhoria da qualidade ambiental da bacia.

\subsection{Participação dos setores usuários nos valores de cobrança}

A cobrança pelo uso da água é um dos instrumentos que coaduna para a regulação dos usos na bacia hidrográfica, tentando equilibrar oferta e demanda como salienta Munck (2006) e Pessoa (2002), quando objetiva o uso racional da água.

Para compreender o cenário da bacia do Rio Doce com relação aos principais usos e sua contribuição com a cobrança pelo uso dos recursos hídricos, optou-se por realizar um recorte do ano de 2018 para verificar a participação dos segmentos nos valores cobrados.

O Gráfico 1 apresenta os usuários de água da bacia do Rio Doce, que se dividem em cinco setores. 


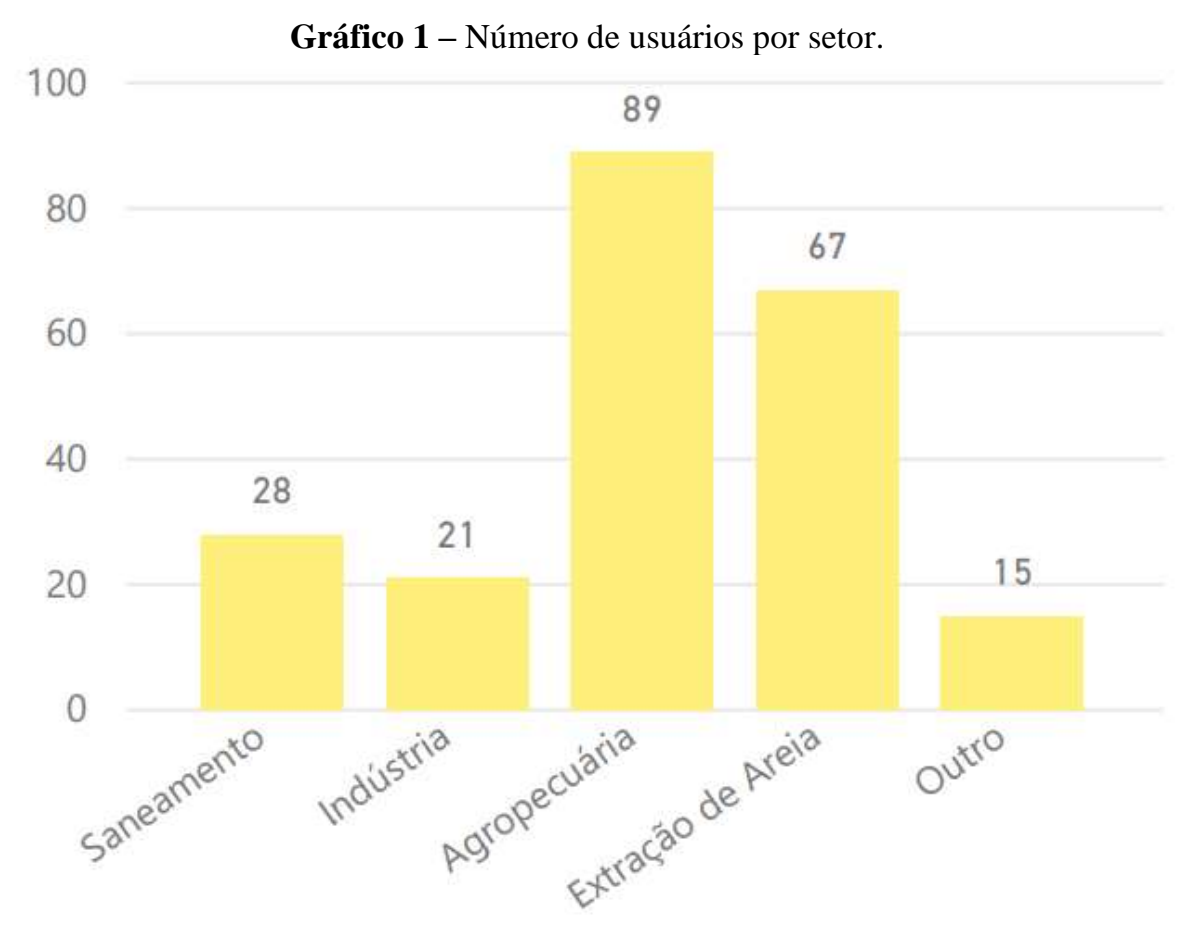

Fonte: ANA (2018b).

Foi identificado um total de 220 usuários, dos quais o setor agropecuário é o mais representativo (40,45\%). Conforme visto no PIRH do Rio Doce, a agropecuária está entre as principais atividades econômicas presentes na bacia, abrangendo atividades como as lavouras tradicionais, reflorestamento, cultura de café, cana-de-açúcar e criação de gado leiteiro e de corte e suinocultura. Em seguida aparecem a extração mineral de areia (30,45\%), o setor de saneamento $(12,72 \%)$ e o setor industrial $(9,54 \%)$ representado pela indústria de celulose, siderurgia, laticínios e produção sucroalcooleira (Igam, 2010).

O Gráfico 2 apresenta a participação desses setores no que tange aos valores cobrados e arrecadados na bacia do Rio Doce.

Gráfico 2 - Valores cobrados e arrecadados por setor.

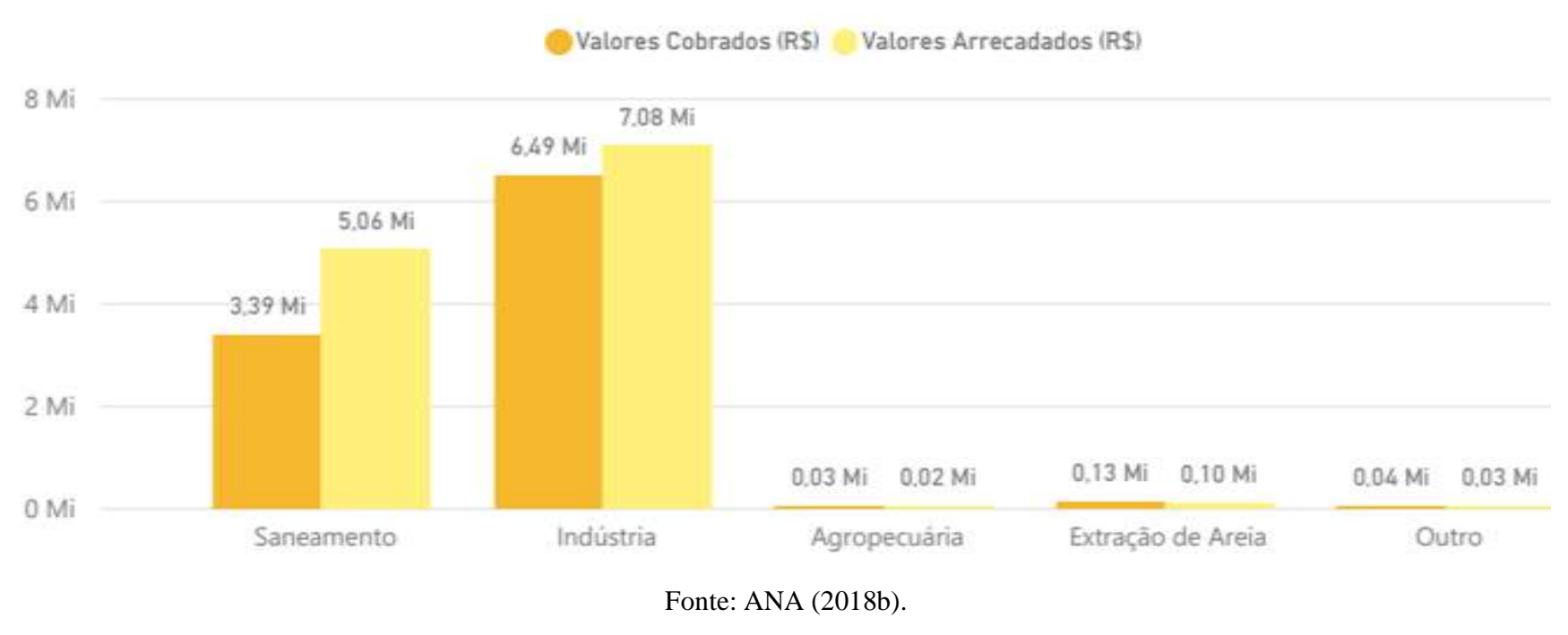

Observa-se que os setores industrial e de saneamento são destaques nos valores cobrados e arrecadados. Reitera-se que a diferença entre o valor cobrado e arrecadado é devido à acumulação de montantes de anos anteriores, o que resultou em valores de arrecadação maiores que os valores cobrados. 
O Gráfico 3 ilustra as vazões utilizadas por cada setor.

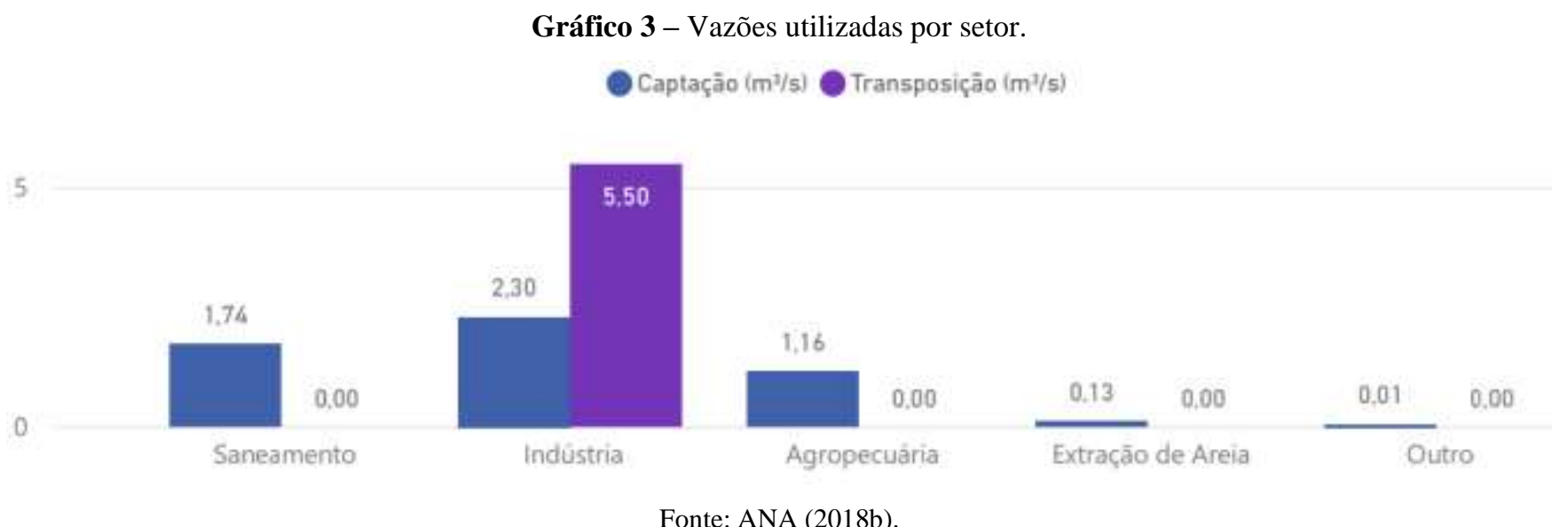

A indústria apresenta a maior contribuição devido aos valores pagos pela transposição de água nesse setor. Comparando-se os gráficos anteriores é possível perceber que apesar da maioria dos usuários serem do setor agropecuário, é o setor industrial o responsável pelos maiores montantes cobrados e arrecadados pela bacia, dadas as vazões utilizadas, e em segunda colocação, tem-se o saneamento como o maior usuário pagante.

Sobre a representatividade desses setores, Bernardes e Broch (2015), estudando a evolução histórica da cobrança em bacias de domínio da União, constataram que a bacia do Rio Doce é a única de domínio da União com cobrança, em que o setor industrial é o principal contribuinte do valor total cobrado e arrecadado, ficando à frente do setor de saneamento.

Um fato a ser observado é que apesar do setor agropecuário ser o terceiro no ranking dos volumes captados, não possui grande representatividade nos valores cobrados e arrecadados. Conforme Relatório elaborado pela Coordenação de Sustentabilidade Financeira e Cobrança da ANA, que discorre sobre a experiência brasileira em cobrança pelo uso de recursos hídricos, identificou que tal setor paga 40 vezes menos que o preço dos demais usuários da bacia (ANA, 2018c).

O lançamento de efluentes também é um parâmetro que influencia nos valores unitários. No que diz respeito a esse lançamento, o setor de saneamento corresponde a 83,6\% do total (11,36 Mi kg de $\mathrm{DBO}_{5,20 / a n o}$. Em segundo lugar aparece o setor industrial (15,5\%). Tal valor pode ser explicado pelas tipificações das atividades industriais desenvolvidas na bacia do Rio Doce, como a indústria de celulose e siderurgia de grande porte que não possuem características que demandem grandes concentrações de $\mathrm{DBO}_{5,20}$ para o efluente produzido (ANA, 2018b).

De maneira geral é possível identificar uma grande dependência do setor industrial na arrecadação dos valores de cobrança, isto porque $9,54 \%$ são responsáveis pela arrecadação de mais da metade do total (57,6\%). Já o setor de saneamento paga 41,2\% do montante total arrecadado. Ou seja, os dois setores representam 98,8\% do total de arrecadação.

Diante disso, o objetivo de uso racional da água proposto pela PNRH pode ser questionado, uma vez que apenas dois setores são os principais usuários pagantes, e os demais setores $(77,4 \%)$ possuem participação financeira muito baixa $(1,2 \%)$.

\subsection{Aplicação dos recursos de cobrança na bacia do Rio Doce}

O terceiro objetivo da cobrança pelo uso de recursos hídricos disposto na PNRH contempla a obtenção de recursos para a realização de intervenções na bacia hidrográfica em questão. O artigo 22 da Lei nº 9.433/1997 estabelece que os valores arrecadados com a cobrança serão aplicados prioritariamente na bacia hidrográfica em que forem gerados e serão utilizados no financiamento de estudos, programas, projetos e obras incluídos nos planos de recursos hídricos; e no pagamento de despesas de implantação e custeio do SINGREH (Brasil, 1997). 
Particularmente, tratando-se da bacia do Rio Doce, em outubro de 2011 foi firmado um contrato entre a ANA e o IBio AGB-Doce (Contrato de Gestão no 72/2011), entidade delegatária escolhida pelo CBH-Doce (Deliberação CBH-Doce n ${ }^{\circ}$ 30/2011 e no 46/2015) e aprovada pelo Conselho Nacional de Recursos Hídricos - CNRH (Resolução CNRH nº 130/2011 e nº 168/2015). O contrato estabeleceu que os valores arrecadados pela ANA devem ser repassados integralmente ao IBio, que possui a atribuição de desembolsar os recursos, que devem ser aplicados no âmbito do PIRH e conforme as diretrizes estabelecidas no Plano de Ação de Recursos Hídricos (PARH), ambos aprovados pelo CBH-Doce (ANA, 2011).

Para esclarecer, o PARH é uma parte integrante do PIRH Doce, e consiste em um instrumento de orientação das ações definidas no plano de bacia que serão executadas pelo IBio com os recursos da cobrança pelo uso (ANA, 2014). Segundo o IBio (2018) foi gerado um plano de ação para cada unidade de gerenciamento da bacia Hidrográfica do Rio Doce, com objetivo de atender peculiaridades de cada região da bacia, com programas prioritários de acordo com a realidade de cada Unidade de Gestão.

O PIRH Doce estabeleceu metas de gestão na bacia colocadas em hierarquia, conforme critérios de urgência e relevância, discutidos no âmbito dos $\mathrm{CBH}$ 's. Foram concebidos 71 programas de intervenção na bacia, agrupados em áreas estratégicas: (i) qualidade da água - enquadramento; (ii) quantidade de água - balanço hídrico; (iii) susceptibilidade a enchentes; (iv) universalização do saneamento; (v) incremento de áreas legalmente protegidas; (vi) implementação dos instrumentos de gestão de recursos hídricos; e (vii) implementação das ações do PIRH Doce (Igam, 2010).

A partir da definição das metas e programas de intervenção, e a definição das demandas urgentes, no ano de 2012 foi aprovado o Plano de Aplicação Plurianual da Bacia do Rio Doce (PAP Doce) para o período 2012 a 2015 pela Deliberação Normativa CBH-Doce $n^{\circ}$ 32/2012, posteriormente alterado pela Deliberação CBH-Doce $n^{\circ}$ 42/2014. Na sequência foi aprovada a Deliberação CBH-Doce n 48/2015, que institui o PAP Doce para o período de 2016 a 2020.

Para contextualizar, o PAP constitui um instrumento básico e harmonizado de orientação dos estudos, planos, projetos e ações a serem executados com recursos da cobrança pelo uso da água em toda a bacia Hidrográfica do Rio Doce e recursos externos (IBio, 2018). Assim, resumidamente, o PAP disciplina a aplicação dos recursos arrecadados com a cobrança e de outras fontes de receita, como por exemplo, recursos oriundos de fundos setoriais como os de recursos hídricos (CT-Hidro, Fhidro-MG e Fundágua-ES), de meio ambiente, doações realizadas por entidades privadas e recursos provenientes de financiamentos (Brasil, 2015).

Segundo a Deliberação CBH-Doce n 48/2015 os seguintes programas do PIRH Doce e PARH's das bacias afluentes, que são considerados prioritários (Brasil, 2015), são demonstrados no Quadro 1. 
Quadro 1 - Programas prioritários definidos pelos PIRH Doce e PARHs das Bacias Afluentes do Rio Doce.

\begin{tabular}{|l|l|}
\hline \multicolumn{1}{|c|}{ Área } & \multicolumn{1}{c|}{ Programa } \\
\hline $\begin{array}{l}\text { Qualidade da Água/ } \\
\text { Enquadramento }\end{array}$ & P11 - Programa de Saneamento da Bacia \\
\hline $\begin{array}{l}\text { Disponibilidade de Águas/ } \\
\text { Balanço Hídrico }\end{array}$ & P21 - Programa de Incremento de Disponibilidade Hídrica \\
\hline Susceptibilidade a Enchentes & P24 - Programa de Incentivo ao Uso Racional de Água na Agricultura \\
\hline Universalização do Saneamento Produtor de Água
\end{tabular}

Fonte: Autores, baseado em Brasil (2015).

Ao observar os programas é possível constatar que a bacia do Rio Doce enfrenta demandas de diferentes tipos, com destaque para as medidas referentes ao saneamento básico, combate de cheias e controle de erosão.

De fato, tais problemas estão entre os principais citados no prognóstico do PIRH Doce. Além da suscetibilidade dos solos da região a erosão, outros fatores agravam o contexto: o manejo inadequado do solo (provocado pelas pastagens e plantio de eucalipto) e o desmatamento generalizado favorecem condições para o aumento dos processos erosivos, que assoreiam os leitos dos rios na bacia. Soma-se a esse processo o lançamento inadequado de resíduos de mineração, industriais e domésticos, que acentua continuamente o assoreamento e a degradação da qualidade da água. Algumas cidades ocuparam a planície de inundação dos rios e em períodos de chuva mais severos são atingidas por alagamentos (Igam, 2010).

Para correlacionar os programas estabelecidos no âmbito do PIRH Doce e a aplicação dos recursos advindos da cobrança, foram obtidas informações disponibilizadas em um relatório mais recente elaborado pela entidade delegatária, referente ao Contrato de Gestão ANA 72/2011 (IBio, 2018). A Tabela 3 apresenta um cenário do repasse dos valores arrecadados com a cobrança pelo uso da água e porcentagem de desembolso, do início da implementação da cobrança até o ano de 2018. 
Tabela 3 - Repasse dos recursos arrecadados com a cobrança e desembolso (em R\$).

\begin{tabular}{c|r|r|r|r|r}
\hline PERIODO & \multicolumn{1}{|c|}{ REPASSE } & RENDIMENTO & $\begin{array}{r}\text { REPASSE + } \\
\text { RENDIMENTO }\end{array}$ & DESEMBOLSO & $\begin{array}{c}\text { índice de } \\
\text { Desembolso } \\
\text { Anual }\end{array}$ \\
\hline 2012 & $2.796 .126,41$ & $39.323,76$ & $2.835 .450,17$ & $704.219,60$ & $24,84 \%$ \\
\hline 2013 & $6.446 .901,79$ & $139.732,54$ & $6.586 .634,33$ & $3.477 .294,78$ & $52,79 \%$ \\
\hline 2014 & $9.639 .171,09$ & $534.673,02$ & $10.173 .844,11$ & $3.601 .634,13$ & $35,40 \%$ \\
\hline 2015 & $9.843 .651,00$ & $781.010,53$ & $10.624 .661,53$ & $5.319 .610,37$ & $50,07 \%$ \\
\hline 2016 & $9.899 .045,00$ & $1.626 .158,13$ & $11.525 .203,13$ & $7.844 .365,32$ & $68,06 \%$ \\
\hline 2017 & $11.928 .716,58$ & $1.447 .447,16$ & $13.376 .163,74$ & $5.868 .445,07$ & $43,87 \%$ \\
\hline 2018 & $11.680 .769,86$ & $1.431 .694,82$ & $13.112 .464,68$ & $3.103 .844,49$ & $23,67 \%$ \\
\hline TOTAL & $\mathbf{6 2 . 2 3 4 . 3 8 1 , 7 3}$ & $\mathbf{6 . 0 0 0 . 0 3 9 , 9 6}$ & $\mathbf{6 8 . 2 3 4 . 4 2 1 , 6 9}$ & $\mathbf{2 9 . 9 1 9 . 4 1 3 , 7 6}$ & $\mathbf{4 3 , 8 5 \%}$ \\
\hline
\end{tabular}

Fonte: Adaptado de IBio (2018).

Sobre o processo de repasse dos recursos oriundos da cobrança, a ANA (2018b) esclarece que enquanto o montante arrecadado não é repassado ao IBio ABG-Doce, são gerados rendimentos financeiros. Assim, a parcela efetivamente repassada para o IBio AGB-Doce na tabela considera rendimentos financeiros mais os montantes repassados pela agência. As diferenças observadas entre os valores constituem montante a serem repassado no ano seguinte.

A parcela "desembolso" refere-se aos recursos que são efetivamente aplicados nos programas, ações e estudos definidos pelo PIRH Doce. Considera também o pagamento de despesas de implantação e custeio administrativo da entidade delegatária, que é limitado a 7,5\% dos valores arrecadados com a cobrança (Brasil, 1997).

A Tabela 4 apresenta a situação de desempenho da agência em relação à meta contratual.

Tabela 4 - Índice de desempenho em relação às metas contratuais (2012 a 2018).

\begin{tabular}{c|c|c|c}
\hline PERIODO & $\begin{array}{c}\text { Meta do } \\
\text { Contrato }\end{array}$ & $\begin{array}{c}\text { indice de } \\
\text { Desembolso } \\
\text { Anual }\end{array}$ & $\begin{array}{c}\text { Desempenho } \\
\text { Anual }\end{array}$ \\
\hline 2012 & $10,00 \%$ & $24,84 \%$ & $248,40 \%$ \\
\hline 2013 & $20,00 \%$ & $52,79 \%$ & $263,95 \%$ \\
\hline 2014 & $35,00 \%$ & $35,25 \%$ & $100,71 \%$ \\
\hline 2015 & $50,00 \%$ & $50,07 \%$ & $100,14 \%$ \\
\hline 2016 & $60,00 \%$ & $68,06 \%$ & $113,43 \%$ \\
\hline 2017 & $60,00 \%$ & $43,87 \%$ & $73,12 \%$ \\
\hline 2018 & $65,00 \%$ & $23,67 \%$ & $36,42 \%$ \\
\hline
\end{tabular}

Fonte: Adaptado de IBio (2018).

Nota-se que há uma tendência de aumento gradual na meta de desembolso (ANA, 2011). Tal gradualidade foi estabelecida devido às dificuldades por todas as agências delegatárias enfrentadas nos primeiros anos de instituição da cobrança, inerentes à complexidade de sua atuação, como a multiplicidade de contratos e regras específicas, impostos por cada um dos entes federativos (ANA, 2014). 
Até o ano de 2016 o IBio esteve adimplente quanto ao cumprimento dos percentuais de desembolso anual e acumulado. Analisando-se informações disponibilizadas em Acórdão do Tribunal de Contas da União - auditoria realizada em 2016 na bacia do Rio Doce - foi possível perceber que o PAP foi uma ferramenta importante ao IBio. Isso permitiu a agência melhorar seu planejamento e agilizar o desembolso financeiro, uma vez que o CBH-Doce definiu os programas prioritários, dispostos PIRH Doce e PARH's das Bacias Afluentes do Rio Doce (Brasil, 2018a).

Por meio da Tabela 4 nota-se que a partir do ano de 2017 o IBio passou a demonstrar insuficiência no desembolso anual, tendo ocorrido em 2018 o menor índice de desembolso do período em análise, com apenas 23,67\%.

De acordo com o IBio (2018), os anos de 2017 e 2018 foram de muitos desafios, tanto financeiramente, quanto de contratações. Isso porque o valor correspondente ao custeio da agência segundo a PNRH (7,5\%) tem sido considerado insuficiente, frente a demanda de programas e contratações a serem executadas, que exigem aumento de recursos humanos e qualificação profissional.

De acordo com o Relatório do exercício de 2018, a equipe de funcionários passou por complexa reestruturação e cenário de insegurança financeira, assim o IBio passou a atuar com apenas 14 profissionais, sendo o mínimo recomendado de 24. Tal redução refletiu em diminuição da capacidade operacional da gestão dos contratos vigentes e inviabilizaram qualquer nova contratação no período (IBio, 2018).

Outra questão a se evidenciar está na permanência de recursos federais em caixa do IBio. De modo compreensível, o saldo em caixa está relacionado à parcela alocada para o investimento (92,5\%), uma vez que a outra parcela (7,5\%) é integralmente utilizada. Como as metas de desembolso anual e acumulado são inferiores a 100\%, o saldo em caixa aumenta ano a ano (Brasil, 2018b). Desta forma, tal saldo é contrastante com a insuficiência de valores da cobrança para a implementação das ações.

Logo, a incompatibilidade da estrutura do IBio e da sua força de trabalho, em relação ao número significativo de projetos priorizados pelos comitês, e também a burocracia inerente à gestão de recursos financeiros de origem pública, têm refletido diretamente no alcance das metas definias pelo PIRH Doce, e, portanto, comprometem o objetivo da cobrança de obtenção de recursos para a realização de intervenções na bacia hidrográfica em questão.

\section{Considerações Finais}

Analisando-se o histórico de valores cobrados e arrecadados na bacia do Rio Doce, foi possível constatar um aumento gradativo nos montantes arrecadados. Entretanto, o índice de inadimplência é considerado relativamente alto, se comparada à média de inadimplência das demais bacias interestaduais.

Apesar dos avanços obtidos desde o primeiro ano da sua aprovação, o estudo permitiu verificar que a cobrança apresenta limitações na bacia em questão, no que tange ao exposto nos objetivos do trabalho. Os valores cobrados estão distantes dos arrecadados, como consequência direta há o comprometimento ao atendimento das ações delimitadas pelo PIRH Doce, como também tem acontecido em outras bacias de domínio da União. Ademais, nota-se que há uma dependência de uma parcela pequena de usuários de grande porte, pois possuem grande influência nas arrecadações.

Outra questão a se ponderar é que a legislação atual permite que apenas 7,5\% do orçamento sejam utilizados no pagamento de despesas de implantação e custeio administrativo dos órgãos e entidades integrantes do Sistema Nacional de Gerenciamento de Recursos Hídricos. Entretanto esse valor tem sido insuficiente, o que gera prejuízos nas metas de desembolso dos recursos repassados pela ANA ao IBio.

Dado o exposto, os recursos financeiros para fomentar as intervenções na bacia não devem se limitar apenas a arrecadação obtida com a cobrança, sendo fundamental a articulação entre os diferentes atores e o estímulo da busca de outras fontes de recursos (como fundos setoriais, bancos de desenvolvimento, prestadores de serviços de saneamento. 
Para o real cumprimento dos objetivos da cobrança pelo uso da água faz-se necessário um engajamento dos atores do SINGREH, comunidade científica e política, de modo a estimular e fomentar estudos estratégicos, realizar o acompanhamento dos seus resultados, visando ao aprimoramento contínuo do instrumento da cobrança. Assim, deve-se criar um ambiente de constante consolidação e melhoria do instrumento, para de fato induzir e estimular a conservação, o manejo integrado e a recuperação dos recursos hídricos.

Recomenda-se para trabalhos futuros realizar uma comparação entre a cobrança dos recursos hídricos na Bacia Hidrográfica do rio Doce com outras bacias de domínio da União.

\section{Referências}

Almeida, J. R. (2018). A cobrança pelo uso da água como instrumento de gestão de bacias hidrográficas: um estudo dos modelos de cobrança aplicados no Brasil e na França. Monografia de Graduação, Universidade Federal de Santa Catarina, Florianópolis, SC, Brasil.

ANA - Agência Nacional de Águas e Saneamento Básico. (2011). Contrato n. 072-2011: Contrato de Gestão que entre si celebram a Agência Nacional de Águas e o Instituto BioAtlântica.

ANA - Agência Nacional de Águas e Saneamento Básico. (2013). Alternativas organizacionais para gestão de recursos hídricos. Cadernos de Capacitação em Recursos Hídricos, v.3, Brasília. https://capacitacao.ead.unesp.br/.

ANA - Agência Nacional de Águas e Saneamento Básico. (2014). Agência de Água - o que é, o que faz e como funciona? Cadernos de Capacitação em Recursos Hídricos, v.4, Brasília. https://capacitacao.ead.unesp.br/.

ANA - Agência Nacional de Águas e Saneamento Básico. (2016). Encarte Especial sobre a Bacia do Rio Doce: Rompimento da barragem em Mariana/MG. http://arquivos.ana.gov.br/RioDoce/EncarteRioDoce_22_03_2016v2.pdf.

ANA - Agência Nacional de Águas e Saneamento Básico. (2017). Conjuntura dos recursos hídricos no Brasil 2017: relatório pleno. http://conjuntura.ana.gov.br/.

ANA - Agência Nacional de Águas e Saneamento Básico. (2018a). Nota Técnica n. 12/2018. Nota Técnica nº 12/2018/CSCOB/SAS: subsídios ao CNRH para definição dos mecanismos e valores a serem cobrados pelo uso de recursos hídricos de domínio da União na Bacia Hidrográfica do Rio Doce.

ANA - Agência Nacional de Águas e Saneamento Básico. (2018b). Informativos de Cobrança. https://www.ana.gov.br/gestao-da-agua/cobranca/informativosda-cobranca.

ANA - Agência Nacional de Águas e Saneamento Básico. (2018c). Nota Informativa $n^{o}$ 5/2018/CSCOB/SAS. Diálogo Político OCDE/Brasil: Definição e Governança dos Instrumentos Econômicos para a Política De Recursos Hídricos - Coordenação de Sustentabilidade Financeira e Cobrança (CSCOB).

ANA - Agência Nacional de Águas e Saneamento Básico. (2019). Notícias: ANA abre audiência pública sobre procedimentos para cobrança pelo uso da água de domínio da União. 2019. https://www.ana.gov.br/noticias/ana-abre-audiencia-publica-sobre-procedimentos-para-cobranca-pelo-uso-da-agua-de-dominioda-uniao.

Bernardes, F. S., \& Broch, S. (2015). O Histórico de cobrança pelo uso de água em bacias hidrográficas de domínio da união. In Anais XXI Simpósio Brasileiro de Recursos Hídricos. Brasília. http://www.evolvedoc.com.br/sbrh/.

Brasil. (1988). Constituição da República Federativa do Brasil. Organizado por Cláudio Brandão de Oliveira: Roma Victor.

Brasil. (1997). Lei $n^{\circ}$ 9.433, de 8 de janeiro de 1997. Institui a Política Nacional de Recursos Hídricos, cria o Sistema Nacional de Gerenciamento de Recursos Hídricos, regulamenta o inciso XIX do art. 21 da Constituição Federal, e altera o art. $1^{\circ}$ da Lei n $^{\circ} 8.001$, de 13 de março de 1990 , que modificou a Lei n ${ }^{\circ} 7.990$, de 28 de dezembro de 1989.

Brasil. (2011a). Resolução CNRH n .123, de 29 de junho de 2011. Aprova os valores e mecanismos para cobrança pelo uso dos recursos hídricos na bacia hidrográfica do rio Doce.

Brasil. (2011b). Deliberação CBH-Doce n. 26, de 31 de março de 2011. Dispõe sobre mecanismos e valores de cobrança pelo uso de recursos hídricos na bacia hidrográfica do rio Doce.

Brasil. (2013). Resolução n. 1346, de 18 de novembro de 2013. Dispõe sobre os procedimentos administrativos atinentes à recuperação de créditos administrados pela Agência Nacional de Águas e abertura de processos de cobranças.

Brasil. (2015). Deliberação ad referendum n. 48, de 01 de dezembro de 2015. Institui o Plano de Aplicação Plurianual da Bacia Hidrográfica do Rio Doce para o período de 2016 à 2020.

Brasil. (2018a). Tribunal de Contas da União - TCU. Acórdão n. 1749/2018, Processo 016.107/2016-0. Plenário, Rel. Min. Walton Rodrigues. Secretaria de Controle Externo no Estado de Minas Gerais - SECEX/MG.

Brasil. (2018b). Deliberação CBH-DOCE n. 69, de 12 de junho de 2018b. Dispõe sobre a atualização dos mecanismos e valores de cobrança pelo uso de recursos hídricos na Bacia Hidrográfica do rio Doce. 
CBH-Doce - Comitê de Bacia Hidrográfica do Rio Doce. (2015). Cobrança e arrecadação 2015. http://www.cbhdoce.org.br/documentos/cobranca-earrecadacao.

Fonseca, E. R., Modesto, F. A., Carneiro, G. C. A., Lima, N. F. S. \& Monte-Mor, R. C. de A. (2020). Conflitos pelo uso da água na Bacia Hidrográfica do rio São Francisco - Estudos de caso no Estado da Bahia. Research, Society and Development, 9(9), e823997929. https://doi.org/10.33448/rsd-v9i9.7929.

Funarbe - Fundação De Apoio à Universidade Federal de Viçosa. (2013). Estudos de aprimoramento dos mecanismos de cobrança da bacia hidrográfica do rio Doce. Relatório Técnico. Viçosa, MG.

IBio - Instituto BioAtlântica. (2018). Relatório de gestão do exercício de 2018. http://www.cbhdoce.org.br/wp-content/uploads/2014/01/1.-Relat\%C3\%B3riodeGest\%C3\%A3o_2018_-CG-ANA-072-2011.pdf.

Igam - Instituto Mineiro de Águas. (2010). Plano Integrado de Recursos Hídricos da Bacia do Rio Doce. Belo Horizonte, Convênio Igam/ANA/IEMA.

Leal, S. G. R. (2010). O impacto da cobrança pelo uso de recursos hídricos na irrigação. Dissertação de Mestrado, Universidade Federal de Ouro Preto, Ouro Preto, MG, Brasil.

Mittermeier, R. A. et al. (2005). Hotspots revisitados: as regiões biologicamente mais ricas e ameaçadas do planeta: mata Atlântica e Cerrado: Conservação Internacional. Recuperado de: http://www.conservation.org/global/brasil/publicacoes/Documents/capa_hots pots.pdf.

Munck, R. C. (2006). Uso dos recursos hídricos: o caso da cobrança na bacia do Rio Paraíba do Sul. Dissertação de Mestrado, Universidade de Brasília, Brasília, DF, Brasil.

OCDE - Organisation for Economic Cooperationand Development. (2017). Cobranças pelo uso de recursos hídricos no Brasil: caminhos a seguir: Éditions OCDE.

Pessoa, C. A. P. (2002). Cobrança sobre os usos da água como instrumento econômico de gestão: o caso do reservatório de Salto Grande. Dissertação de Mestrado, Universidade de São Paulo, São Carlos, SP, Brasil.

Prodanov, C. C., \& Freitas, E. C. (2013). Metodologia do Trabalho Científico: Métodos e Técnicas da Pesquisa e do Trabalho Acadêmico. [e-book]. Novo Hamburgo: Feevale. https://aedmoodle.ufpa.br/pluginfile.php/291348/mod_resource/content/3/2.1-E-book-Metodologia-do-Trabalho-Cientifico-2.pdf

Rosa, D. W. B. (2019). Aprimoramento da cobrança pelo uso de recursos hídricos no estado de minas gerais: perspectivas dos integrantes do sistema estadual de gestão de recursos hídricos. Revista de Gestão de Água da América Latina, 16 (4). https://www.abrh.org.br/OJS/index.php/REGA/article/view/235.

Silva, A. C. R. (2003). Metodologia da pesquisa aplicada à contabilidade - orientações de estudos, projetos, artigos, relatórios, monografias, dissertações, teses: Atlas.

Silva, T. S. (2020). A cobrança pelo uso de recursos hídricos no Comitê da Bacia Hidrográfica do rio Araguari - MG. Dissertação de Mestrado, Universidade Federal de Uberlândia, Uberlândia, MG, Brasil.

Thomas, P. T. (2002). Proposta de uma metodologia de cobrança pelo uso da água vinculada à escassez. Dissertação de Mestrado, Universidade Federal do Rio de Janeiro, Rio de Janeiro, RJ, Brasil.

Turrioni, J. B., \& Mello C. H. P. (2012). Metodologia de pesquisa em engenharia de produção e gestão de processos: Elzevir.

Vera, F. H. A. (2014). Atuação da cobrança pelo uso da água de domínio da união como instrumento de gestão de recursos hídricos na Bacia Hidrográfica do Rio São Francisco. Dissertação de Mestrado, Universidade Federal de Pernambuco, Recife, PE, Brasil.

Yassuda, E. R. (1993). Gestão de recursos hídricos: fundamentos e aspectos institucionais. Revista Administração Pública. 27 (2), 5-11. http://bibliotecadigital.fgv.br/ojs/index.php/rap/article/viewFile/8663/7394. 